\title{
Assessment of Resistance Pathways Induced in Arabidopsis thaliana by Hypovirulent Rhizoctonia spp. Isolates
}

\author{
Michal Sharon, Stanley Freeman, and Baruch Sneh
}

First and third authors: Department of Molecular Biology and Ecology of Plants, The George S. Wise Faculty of Life Sciences, Tel Aviv University, Ramat Aviv, Israel 69978; and second author: Department of Plant Pathology and Weed Research, The Volcani Center, Agricultural Research Organization, Bet Dagan, Israel 20250.

Accepted for publication 23 February 2011.

\begin{abstract}
Sharon, M., Freeman, S., and Sneh, B. 2011. Assessment of resistance pathways induced in Arabidopsis thaliana by hypovirulent Rhizoctonia spp. isolates. Phytopathology 101:828-838.

Certain hypovirulent Rhizoctonia isolates effectively protect plants against well-known important pathogens among Rhizoctonia isolates as well as against other pathogens. The modes of action involved in this protection include resistance induced in plants by colonization with hypovirulent Rhizoctonia isolates. The qualifications of hypovirulent isolates (efficient protection, rapid growth, effective colonization of the plants, and easy application in the field) provide a significant potential for the development of a commercial microbial preparation for application as biological control agents. Understanding of the modes of action involved in protection is important for improving the various aspects of development and application of such preparations. The hypothesis of the present study is that resistance pathways such as systemic acquired resistance (SAR), induced systemic resistance (ISR), and phytoalexins are induced in plants colonized by the protective hypovirulent Rhizoctonia isolates and are involved in the protection of these plants against pathogenic Rhizoctonia. Changes in protection levels of Arabidopsis

ndr1-1, npr1-2/ndr1-1, cim6, wrky70.1, snc1, and pbs3-1) and colonized with the hypovirulent Rhizoctonia isolates compared with that of the wild type (wt) plants colonized with the same isolates confirmed the involvement of induced resistance in the protection of the plants against pathogenic Rhizoctonia spp., although protection levels of mutants constantly expressing SAR genes (sncl and $\operatorname{cim} 6)$ were lower than that of wt plants. Plant colonization by hypovirulent Rhizoctonia isolates induced elevated expression levels of the following genes: PR5 (SAR), PDF1.2, LOX2, LOX1, CORI3 (ISR), and PAD3 (phytoalexin production), which indicated that all of these pathways were induced in the hypovirulent-colonized plants. When SAR or ISR were induced separately in plants after application of the chemical inducers Bion and methyl jasmonate, respectively, only ISR activation resulted in a higher protection level against the pathogen, although the protection was minor. In conclusion, plant colonization with the protective hypovirulent Rhizoctonia isolates significantly induced genes involved in the SAR, ISR, and phytoalexin production pathways. In the studied system, SAR probably did not play a major role in the mode of protection against pathogenic Rhizoctonia spp.; however, it may play a more significant role in protection against other pathogens.
\end{abstract} thaliana mutants defective in defense-related genes (nprl-1, nprl-2,
Pathogenic Rhizoctonia spp. are important soilborne plant pathogens, causing considerable damage to many crop plants, ornamentals, and trees. These pathogens were previously controlled successfully by soil fumigation, mainly with methyl bromide. However, since the use of methyl bromide was prohibited, efforts have been invested in alternative methods of control. A variety of hypovirulent Rhizoctonia isolates have been confirmed to protect pathogenic Rhizoctonia spp. $(21,48,49,57)$, with the efficacy of some of the isolates reaching 75 to $95 \%$ protection (48). In addition, some of the hypovirulent isolates also protected plants against other pathogens such as Pythium ultimum, Pseudomonas syringae (48), and Botrytis cinerea (9); promoted plant growth (21); or formed mycorrhizal associations with orchids (47).

Clarifying the modes of action of this plant protection by the hypovirulent Rhizoctonia isolates is important and may facilitate and advance efficient screening for better protective hypovirulent isolates and, consequently, improved defense of plants against pathogens. The hypovirulent isolates were able to densely colonize the epidermal surfaces of host tissues but did not penetrate the cells (20). The possibilities of protection by antibiotic secretion, mycoparasitism, or competition for root exudates

Corresponding author: B. Sneh; E-mail address: baruchs@tauex.tau.ac.il

doi:10.1094/PHYTO-09-10-0247

(c) 2011 The American Phytopathological Society containing sugars and amino acids were tested but neither was found to be involved (49). The systemic resistance induction by hypovirulent Rhizoctonia isolates was shown by Sneh and Ichielevich-Auster (48). Subsequently, suberin, pectic substances, salicylic acid (SA), peroxidase, 1,3- $\beta$-glucanase (pathogenesisrelated $[\mathrm{PR}]-2$ family), phenylalanine ammonia lyase (PAL), and chitinase (PR-3 family) were found to be involved in the hypovirulent protection of bean plants $(9,24,58)$ but, thus far, there has been no attempt to identify plant resistance reactions induced by hypovirulent Rhizoctonia spp.; specifically, the systemic acquired resistance (SAR) or induced systemic resistance (ISR) pathways.

SAR is a systemic defense network that is induced in plants in response to attack by some pathogens (usually biotrophs) $(3,22)$ and involves SA or its derivative, methyl salicylate, as the key signal (4). SAR was also induced by applying abiotic substances such as benzothiadiazole or Bion (Syngenta), which contains acibenzolar-S-methyl (56). A constitutive expression of SAR may reduce plant fitness (12) although, without SA production or accumulation, SAR did not occur $(4,17)$.

ISR is triggered in plants by a variety of microorganisms and insects, mostly rhizobacteria (51) and necrotrophic fungi (40). It is dependent on jasmonic acid (JA) or its derivative, methyl jasmonate (MeJA), and ethylene (ET) signals, and is independent of SA $(3,42)$. Contrary to SAR, ISR is not associated with PR proteins (54) but a functional NPRl gene is necessary for ISR induction (27). 
Arabidopsis thaliana mutants harboring defective genes involved in plant defense reactions serve as effective tools for identifying genes induced in the plants as a response to pathogen attack or other inducers of plant defense pathways. For example, mutant nprl A. thaliana plants did not activate PR proteins after pathogen infection, even though they accumulated high levels of SA (4). The NPRl gene was also necessary for resistance responses activated by the JA/ET pathway (13) although, in this case, NPR1 was not involved in PR1 transcription (42).

Another important gene involved in plant resistance responses is non-race-specific disease resistance 1 (NDRl), which was necessary for the function of most PR proteins in the subgroup of leucine-zipper within the gene group of leucine-rich repeat nucleotide-binding sites (18). NDRl expression increased after bacterial infection (11) and one of its roles is to maintain resistance $(\mathrm{R})$ proteins in proximity to the membrane (17), and to act as an elicitor signal after the specific resistance-avirulence (RAVR) interaction. NDR1 also serves as a transporter or a receptor for the elicitor signal (11). The $n d r l-1$ null mutant is impaired in reactive oxygen species (ROS) response, both production and sensing (60), which could affect or be affected by the NDR1 role as an SA regulator (33). The gene phytoalexin deficient 4 (PAD4) is located upstream from the SA signal in the SAR pathway (18) and its mRNA levels increased in response to induction of the SAdependent systemic resistance (25). The PR5 gene family was induced by fungal infection and had antifungal activity (28). PR5 transcription was induced in response to activation of the SAR pathway in Arabidopsis and, therefore, is used as a marker for SAR-dependent defense triggering (27). Genes from the lipoxygenase (LOX) family are dioxygenases, and catalyze the hydroperoxidation of specific unsaturated fatty acids in plants, animals, and microorganisms (36). One of their roles is to initiate JA synthesis in plants (45), where they mediate the conversion of linoleic acid to 13-hydroperoxylinolenic acid (2). LOX1 is a 9lipoxygenase gene (2), which is known to be involved in defense responses (32). MeJA or inoculation with the pathogen $P$. syringae increased LOX1 expression for at least $96 \mathrm{~h}$ (36). LOX2 is a 13-lipoxygenase gene (2) which is known to catalyze the first step of the JA biosynthetic pathway, while LOX2 mRNA accumulated rapidly after JA induction (4). Transgenic plants defected in LOX2 did not accumulate JA after wounding although the basal level of JA was unaffected in the transgenic plants (5). The plant defensin 1.2 (PDF1.2) gene encodes a small protein with antifungal activity (39), and its transcription is triggered in response to JA and ET (7) but not SA (3). PDF1.2 is used as an indicator for ISR triggering (27), and blocking $\mathrm{H}_{2} \mathrm{O}_{2}$ production (by using an NADPH inhibitor) also inhibited PDF1.2 induction (23). The A. thaliana coronatine induced3-jasmonic acid-responsive (CORI3/JR1) gene that encodes cysteine lyase (26) was induced in response to coronatine, MeJA, and abscisic acid in a dosagedependent manner (10).

One of the defense mechanisms induced in plants in response to pathogen attack includes the phenylpropanoid pathway (50). van Wees et al. (52) reported that the phytoalexin-related gene $P A D 3$ is essential for $A$. thaliana defense against Alternaria brassicicola. PAD3 encodes the cytochrome P450 enzyme CYP71B15 that catalyzes the last step of camalexin biosynthesis (6). GH3.12/ $A V R P P H B$ susceptible 3 gene (PBS3) in Arabidopsis thaliana (38) was proposed to act upstream from SA, inducing SA biosynthesis, while SA inhibits GH3.12 activity and, hence, regulates its own synthesis (55). A mutant in this gene (pbs3-1) has reduced SA accumulation and SA-dependent gene expression (38). The different pathways of defense (ISR, SAR, and phytoalexins) are entwined (Fig. 1) and, therefore, a change in one may lead to changes in others.

The main objective of this study was to identify the modes of systemic resistance induced in plants in response to hypovirulent
Rhizoctonia isolates against pathogenic Rhizoctonia solani. A. thaliana mutants harboring the above-described defective genes involved in induced resistance pathways were used, which included quantitative real-time polymerase chain reaction (PCR) to identify some of the major genes and pathways involved in the mode of induced resistance in plants, triggered by the hypovirulent Rhizoctonia isolates.

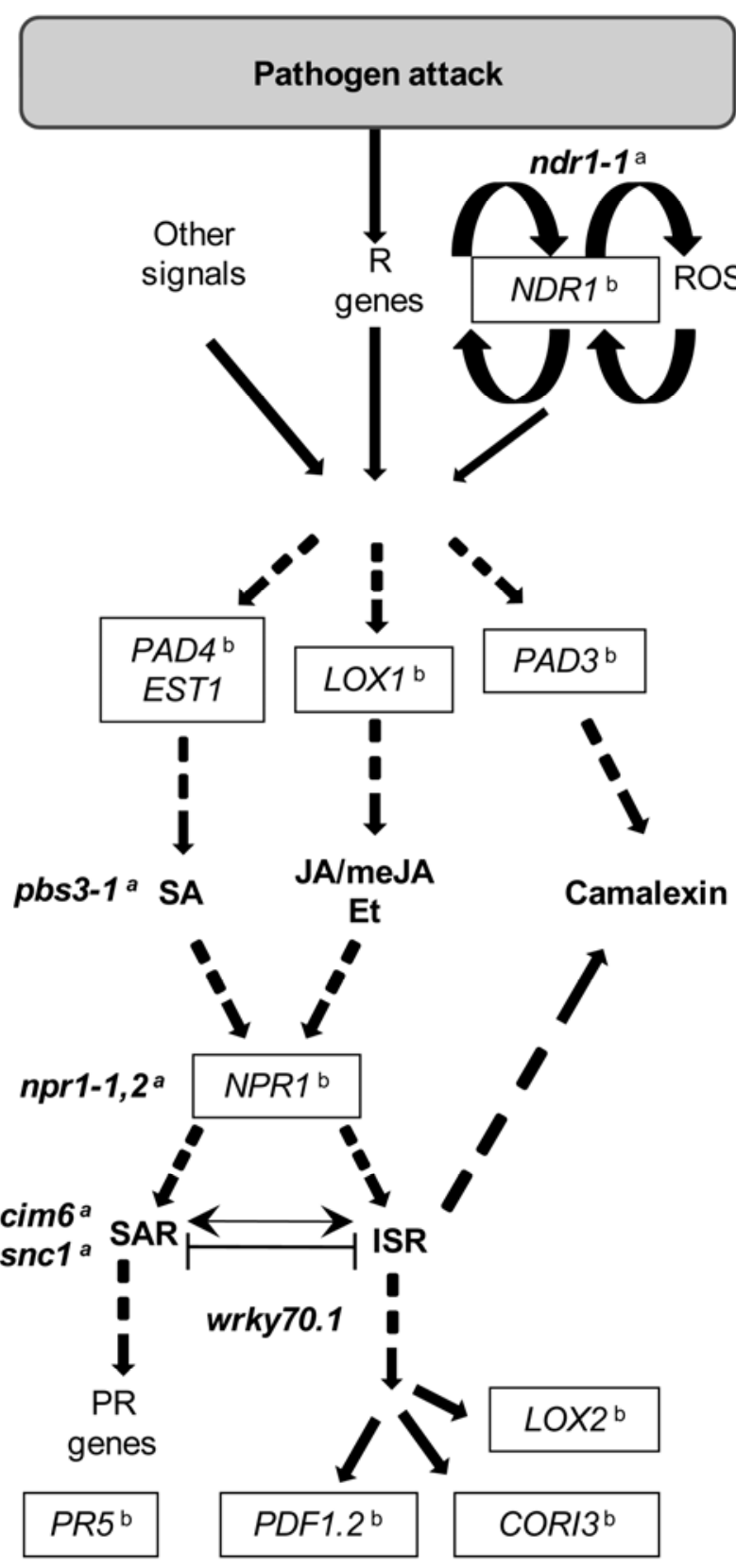

Fig. 1. Induced resistance pathways network. A simplistic diagram illustrating the location of defense-related genes and defective genes of Arabidopsis thaliana mutants utilized in the present study. PAD4 and PR5 are a part of the systemic acquired resistance (SAR) pathway, PAD4 is upstream from salicylic acid (SA) (18), while PR5 is induced in response to SAR activation (27). LOX1, LOX2, CORI3, and PDF1.2 genes are induced in the induced systemic resistance (ISR) pathway. LOX1 is involved in defense responses but its precise function is still unclear, $L O X 2$ catalyzes the first step of jasmonic acid (JA) biosynthesis (2), CORI3 mRNA is induced in response to methyl jasmonate (MeJA), and PDF1.2 encodes a protein with antifungal activity (39). Other genes: $P A D 3$ encodes an enzyme which catalyzes the last step in the phytoalexin camalexin production (6) and NDR1 is involved in reactive oxygen species (ROS) production and accumulation (11). $\mathrm{PR}=$ pathogenesis related, superscript $\mathrm{a}=A$. thaliana mutants, and superscript $\mathrm{b}=$ central genes involved in plant protection. 


\section{MATERIALS AND METHODS}

Media. The following media were prepared and used in this study: water agar (WAcm), consisting of agar at $17 \mathrm{~g} /$ liter (Difco Laboratories, Detroit) in 1 liter of distilled water supplemented with chloramphenicol at $250 \mu \mathrm{g} / \mathrm{ml}$ (Sigma-Aldrich, St. Louis), autoclaved and dispensed at $18 \mathrm{ml}$ per $90-\mathrm{mm}$ plates; Murashige and Skoog (MS) agar (37), prepared and dispensed at $33 \mathrm{ml}$ per 90-mm plate; and yeast extract agar (YDAcm), consisting of $5 \mathrm{~g}$ of yeast extract (Difco Laboratories), $5 \mathrm{~g}$ of peptone (Difco Laboratories), $5 \mathrm{~g}$ of sucrose (Frutarom, Haifa, Israel), and $17 \mathrm{~g}$ of agar (Difco Laboratories) per liter and supplemented with chloramphenicol at $250 \mu \mathrm{g} \mathrm{ml}^{-1}$, dispensed at $18 \mathrm{ml}$ per $90-\mathrm{mm}$ plate.

Fungal and plant material. Hypovirulent binucleate Rhizoctonia isolates Ru18-1, Ru89-1 [AG-B(o)], Rh521, and Ru56-8 (AG-A) (46) and pathogenic isolate RS13 (AG 4 HG-I) (48) were used in this study. Inoculum was prepared using 4-by-4-mm ${ }^{2}$ YDAcm squares, from the fresh hyphal growth of a 3-day-oldcolony.

A. thaliana seed were surface disinfected with sodium hypochlorite/ethanol $(2.5: 75 \%$, vol/vol) for $15 \mathrm{~min}$, washed four times with $100 \%$ ethanol, and dried. The A. thaliana mutants used in the present study are listed in Table 1 .

Development of virulence and protection assays for hypovirulent Rhizoctonia isolates on $A$. thaliana plants in MS plates. Disinfected $A$. thaliana wild type (wt) seed ( $n=25$ to 30 ) were sown at the perimeter of $90-\mathrm{mm}$ MS plates. The plates were sealed with parafilm and incubated overnight at $4^{\circ} \mathrm{C}$. The parafilm was then perforated in four places and the plants incubated at $25^{\circ} \mathrm{C}$ for $12 \mathrm{~h}$ darkness and $12 \mathrm{~h}$ light. Seven days later, the plants were thinned out to leave 20 plants/plate and resealed with perforated parafilm. Ten days later, four squares of YDAcm colonized with each Rhizoctonia isolate were placed at a distance of $1 \mathrm{~cm}$ from the plantlets (control consisted of noncolonized YDAcm) for the virulence assays. For the protection assays, $48 \mathrm{~h}$ later, the plants were challenge inoculated with the pathogenic Rhizoctonia isolate RS13 using a colonized YDAcm square at the center of each plate (Fig. 2). Plant survival was monitored for 14 days from the inoculation with the hypovirulent isolates. The optimal time to evaluate plant survival was found to be 8 days after inoculation with hypovirulent isolates. Results of the protection assay were calculated according to the plant protection formula: plant protection $(\%)=100 \times(A-B) /(C-B)$, where $A=$ percent surviving plants after colonization with the tested hypovirulent isolate and challenge inoculation with the pathogen; $B=$ percent surviving plants after inoculation only with the pathogen, and $C=$ percent surviving noninoculated plants (48). The virulence and protection experiments were performed three times, with six plates per replicate.

Exogenic induction of SAR or ISR. All experiments were carried out on 17-day-old $A$. thaliana seedlings. For treatments to evaluate SAR induction, two 5- $\mu$ l drops were placed on the leaves of each plant as follows: control, sterile distilled water; Bion, $1 \%$ (vol/wt) Bion (acibenzolar-S-methyl) (Syngenta Crop Protection,
Basel, Switzerland); RS13 as the control and, 48 h later, inoculated with the pathogenic Rhizoctonia isolate RS13 (as described in the protection assay); and Bion+RS13, consisting of Bion and, $48 \mathrm{~h}$ later, challenge inoculated with the pathogen.

For ISR induction, a propylene disk ( $8 \mathrm{~mm}$ in diameter) was placed at the center of the plate. Two paper disks $(5 \mathrm{~mm}$ in diameter) were placed on top of the propylene disk and $20 \mu \mathrm{l}$ was added to the paper disks as follows: control, 20\% ethanol; MeJA, $2 \%$ MeJA (Duchefa Biochemie, Haarlem, The Netherlands) in $20 \%$ ethanol; pathogenic Rhizoctonia isolate RS13, prepared as control and, $48 \mathrm{~h}$ later, challenge inoculated with the pathogen (as described in the protection assay); and MeJA+RS13, plants treated with MeJA and, $48 \mathrm{~h}$ later, challenge inoculated with the pathogen.

The plates were sealed and incubated at $25^{\circ} \mathrm{C}$ for 12 and $12 \mathrm{~h}$ (darkness and light), under controlled conditions. After 6 days, plant survival and protection were evaluated as described in the protection assay section. The experiments were performed three times, with six plates per replicate.

Evaluation of defense-related gene expression in $\mathrm{A}$. thaliana. A. thaliana plants were cultured as described in the $A$. thaliana virulence assay (10 plants/plate, 12 plates/treatment, each experiment performed twice). Hypovirulent Rhizoctonia isolates on YDAcm plugs were placed adjacent to each plant (noninoculated YDAcm for the control). The plants were

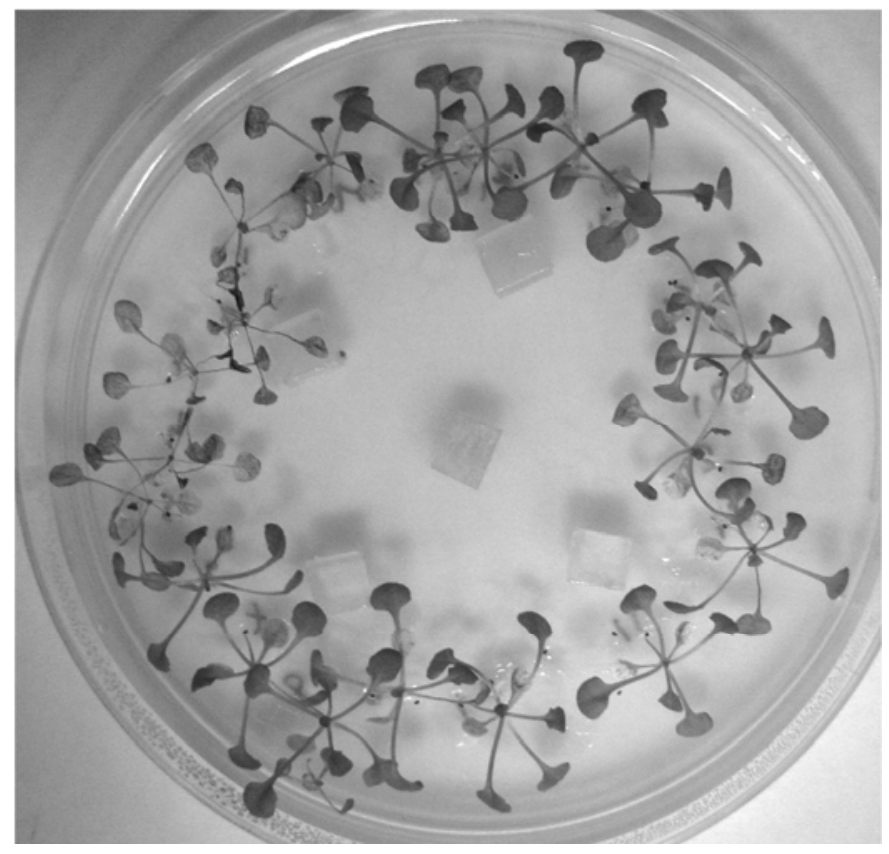

Fig. 2. Protection assay. Arabidopsis thaliana plants inoculated with the hypovirulent isolate Ru89-1 (four colonized yeast extract agar (YDAcm) squares at the periphery of the plate) and, $48 \mathrm{~h}$ later, challenge inoculated with the pathogenic isolate RS13 (a single colonized YDAcm square at the center of the plate). Plant protection evaluation was determined 6 days later.

TABLE 1. Arabidopsis thaliana mutants used in the present study

\begin{tabular}{|c|c|c|c|}
\hline Gene & Reference & TAIR affiliation $^{\mathrm{a}}$ & Remarks \\
\hline nprl-1 & 8 & CS3726 & $\ldots$ \\
\hline nprl-2 & $\ldots$ & CS3801 & $\ldots$ \\
\hline$n d r 1-1$ & 11 & CS6358 & Courtesy of Professor Brian Staskawicz, University of California, Berkeley \\
\hline$n p r 1-2 / n d r 1-1$ & 60 & CS6355 & $\ldots$ \\
\hline $\operatorname{cim} 6$ & 35 & CS6571 & $\ldots$ \\
\hline wrky70.1 & 3 & SALK_025198c & $\ldots$ \\
\hline sncl & 31 & Unknown & Courtesy of Professor Xin Li, University of British Colombia, Vancouver, Canada \\
\hline pbs3-1 & 38 & Unknown & Courtesy of Professor Roger Innes, University of Indiana, Bloomington \\
\hline
\end{tabular}

a The Arabidopsis Information Resource. 
incubated at $25^{\circ} \mathrm{C}$ and at 12 and $12 \mathrm{~h}$ (darkness and light) for $48 \mathrm{~h}$, harvested, immediately frozen in liquid nitrogen, and stored at $-80^{\circ} \mathrm{C}$ before RNA extraction. The plants were finely ground in liquid nitrogen and Tri Reagent (Sigma-Aldrich) was used for RNA extraction according to the manufacturer's instructions, including modifications for reverse-transcription (RT)-PCR (additional centrifugation step of $12,000 \mathrm{rpm}$ for $10 \mathrm{~min}$ at $4^{\circ} \mathrm{C}$ and a wash in $1: 10$ [vol/vol] isopropanol concentration) (Bio-Lab, Jerusalem, Israel). RNA concentration was determined using a NanoDrop spectrometer ND-1000 (Thermo Scientific, Wilmington, DE) and inspected on $1.5 \%$ SeaKem LE agarose gel (Cambrex Bio Science Rockland, Rockland, ME) to confirm that it had not been degraded. If the RNA concentration was sufficient $(>500 \mathrm{ng} / \mathrm{ml}$ ) and of high quality, DNA traces were removed using the TURBO DNA-free kit (Applied Biosystems, Foster City, CA). cDNA was prepared from $1 \mu \mathrm{g}$ of clean RNA using a High-Capacity cDNA Reverse Transcription kit (Applied Biosystems, Foster City, CA) with a primer of oligo-dT (17) . The cDNA was stored at $-80^{\circ} \mathrm{C}$.

Quantitative real-time $\mathrm{PCR}$ reactions to determine gene expression. The reaction volumes were $15 \mu \mathrm{l}$, containing $4 \mu \mathrm{l}$ of cDNA, $2 \mu \mathrm{l}$ of $0.03 \mathrm{mM}$ sense and antisense primers, and $1 \times$ SYBR Premix Ex Taq II Mix, (Takara, Shiga, Japan). The quantitative (q)RT-PCR was performed in a Rotor-Gene 3000 (Corbett Research, Sidney, Australia). Relative quantification of the examined expressed genes was analyzed using the REST-2005 program (41), with $\beta$-tubulin as a reference gene, and the pairwise fixed reallocation randomization test (41) was used to analyze the mean of the technical repeats and independent biological repeats, detecting the relative quantification and the level of significance. For evaluation of difference in expressed genes due to colonization by the hypovirulent Rhizoctonia isolates, the reference condition was noninoculated control plants. For evaluation of difference in expressed genes due to mutation in defense-related genes, the reference condition was wt plants. The qRT-PCR experiments for each treatment consisted of triplicates in five technical repeats performed on two biological repeats. The genes which were used to evaluate their expression levels with the qRTPCR methods are listed in Table 2. All amplicons were 100 bases long.

Statistical analysis. Apart from the qRT-PCR results with the relevant statistics mentioned in the previous section, all of the statistical analyses were performed using the JMP IN program, (version 5.0.1a; SAS Institute, Cary, NC). The results of the virulence and protection assays were transformed according to statistical standards by using arcsine on the square root of the proportion. Two-way analysis of variance $(\alpha=0.05)$ was then used to evaluate whether there were differences between either plant types or treatments, followed by post-hoc Tukey's highly significant difference (HSD) with $\alpha=0.05$ to establish the differences. Similar methods were used for the statistics of plant survival following the exogenic induction of SAR and ISR.

\section{RESULTS}

Development of reliable virulence and protection assays for hypovirulent Rhizoctonia isolates on $A$. thaliana plants in vitro. In the virulence assay, mortality of $A$. thaliana plants infected by the pathogen commenced on the second day after inoculation, increased rapidly by day four, and reached $>97 \%$ by day eight. In contrast, no mortality of plants colonized by the hypovirulent isolates occurred, even after 10 days. The greatest difference in survival rates between the plants infected by the pathogen and those colonized by the hypovirulent Rhizoctonia isolates was from day 8 to 10 , even though the difference between the survival rates of the pathogen-infected plants and the hypovirulent-inoculated plants was constant from day 4 (Tukey's HSD, $P=0.00$ ).

In the protection assay, mortality of $A$. thaliana plants colonized only by the pathogen started as soon as 2 days following inoculation (Fig. 3). Some of the plants which were colonized with the hypovirulent isolates prior to challenge inoculation with the pathogen survived at least 4 to 10 days (minimum of 95 to $19 \%$ survival, respectively); the mortality of the plants at the later periods was probably due to unfavorable conditions resulting from the crowded plates (plants and fungi). The highest difference in protection rates between the protected plants and the pathogen-infected control was on day six (Tukey's HSD, $P=$ 0.00). Therefore, results of the subsequent protection experiments were recorded 6 days after challenge inoculation with the pathogen.

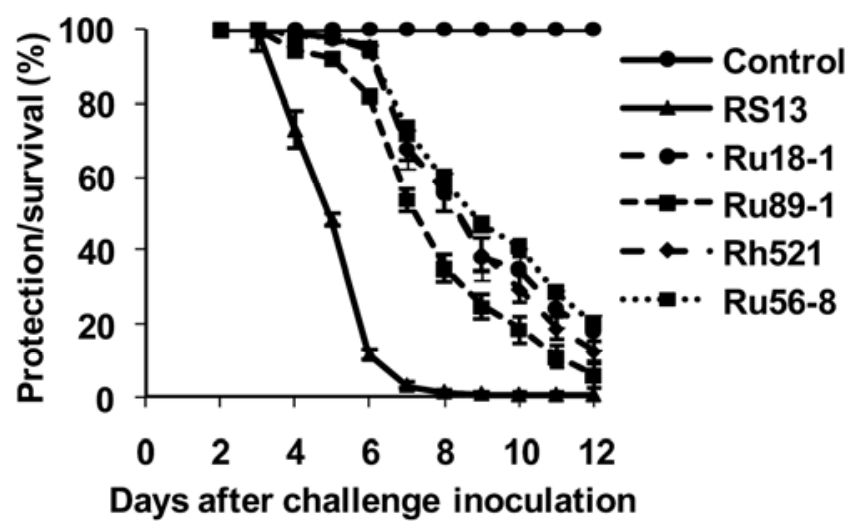

Fig. 3. Development of a protection assay for Rhizoctonia isolates on Arabidopsis thaliana plants. Protection rates of plants grown in vitro on Murashige and Skoog medium and inoculated with Rhizoctonia isolates was calculated as mentioned in the Materials and Methods section. Control = noninoculated plants, pathogenic isolate $=\mathrm{RS} 13$ alone or hypovirulent isolates Ru18-1, Ru89-1, Rh521, or Ru56-8. Plants were challenge inoculated with the pathogenic isolate $48 \mathrm{~h}$ after inoculation with the hypovirulent isolates. Bars represent standard errors of the means. Control and RS13 results indicate the percent survival of the plants rather than the percent protection.

TABLE 2. Primers used to evaluate change in genes expression by using quantitative reverse-transcription polymerase chain reaction analysis

\begin{tabular}{|c|c|c|c|}
\hline \multirow[b]{2}{*}{ Gene } & \multirow[b]{2}{*}{$\mathrm{NCBI}^{\mathrm{a}}$} & \multicolumn{2}{|c|}{ Primers } \\
\hline & & Sense & Antisense \\
\hline Tubulin 9 & NM_118207.2 & TUB9-R: TTTCGGTCTTCCCATCTC & TUB9-L: ATACATTCATCAGCATTCTCAAC \\
\hline Phytoalexin-deficient 4 & AF188329 & PAD4-3R: CTTATCCTCCGATGAACCTCTAC & PAD4-3L: ACCTAACAATTCCAATTCCAATCC \\
\hline Pathogenesis-related gene 5 & NM_106161 & PR5-2R: GTAACGGCGGCGGAGTTC & PR5-2L: TTGTAACCATCTACGAGGCTCAC \\
\hline Coronatine induced 1 & NM_001036628 & CORI3-R: ACTGGTTGGCTCACGCTAC & CORI3-L: TCGGAGGGTTATTGTTTATCTGGAG \\
\hline Lipoxygenase 1 & NM_104376.2 & LOX1-R: GACTATGCTTACTACAATGATTTAG & LOX1-L: CGGTTCTTCCTCTTCTTG \\
\hline Lipoxygenase 2 & NC_003074 & LOX2-R: AGTGAAGTGCGGAACATAGG & LOX2-L: CAATCGTAGTTACCACACCAATC \\
\hline Plant defensin $1.2 A$ & NM_123809.3 & PDF1.2-R: CACATACATCTATACATTGAAAAC & PDF1.2-L: CAGCAAAGAGAACAAGAG \\
\hline $\begin{array}{l}\text { Phytoalexin deficient } 3 \\
\text { Non-race-specific disease }\end{array}$ & NM_113595 & PAD3-R: CGTGGTCAAGGAGACATTAAGG & PAD3-L: CGCAGGAACATCGTAGCC \\
\hline resistance protein 1 & ВТ002004.1 & NDR1-3R: CTATCAAGGACACAAGAAGAAG & NDR1-3L: AACAGCCGATCCATTAGG \\
\hline
\end{tabular}

a National Center for Biotechnology Information affiliation. 


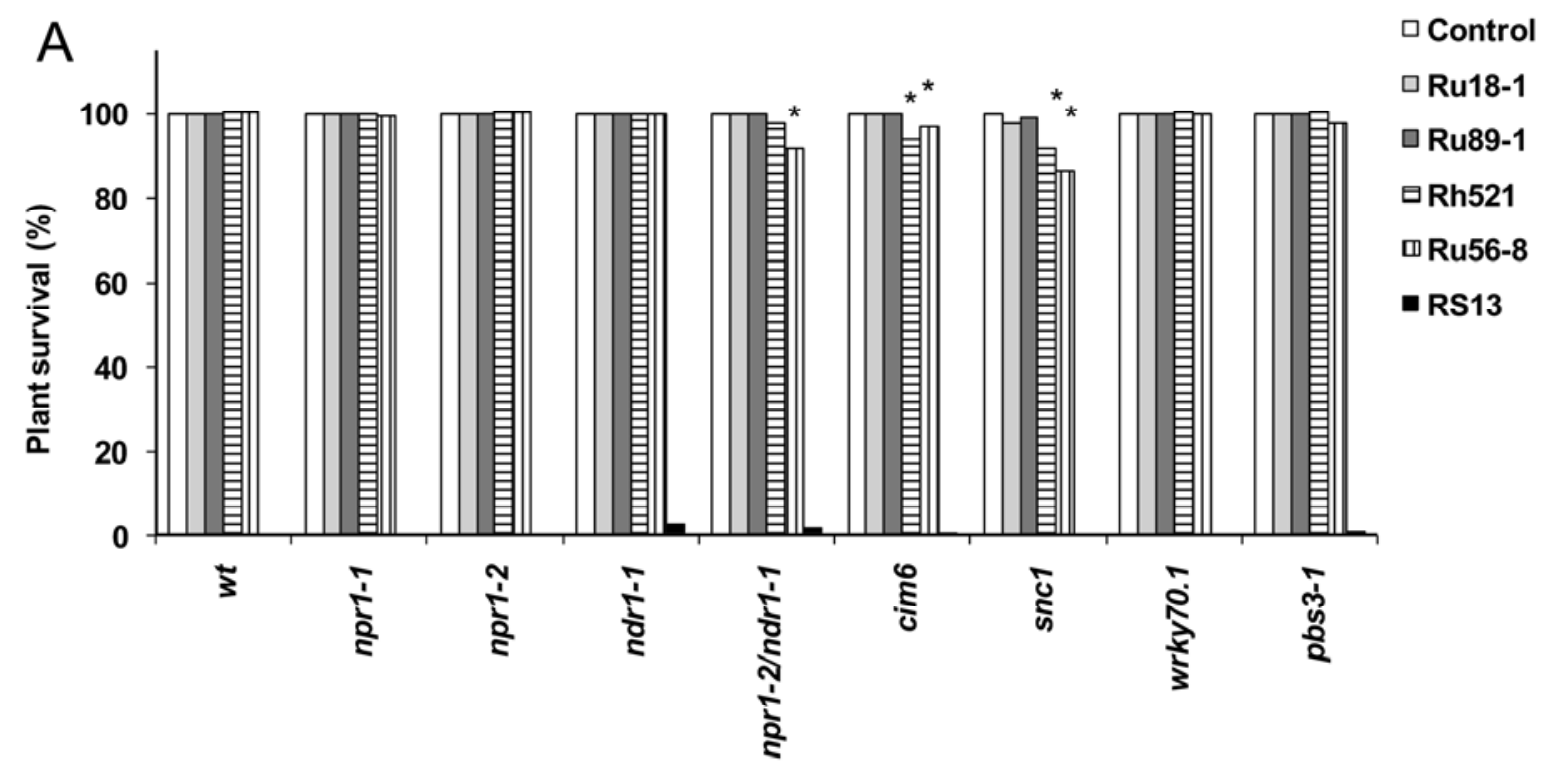

Plant genotype

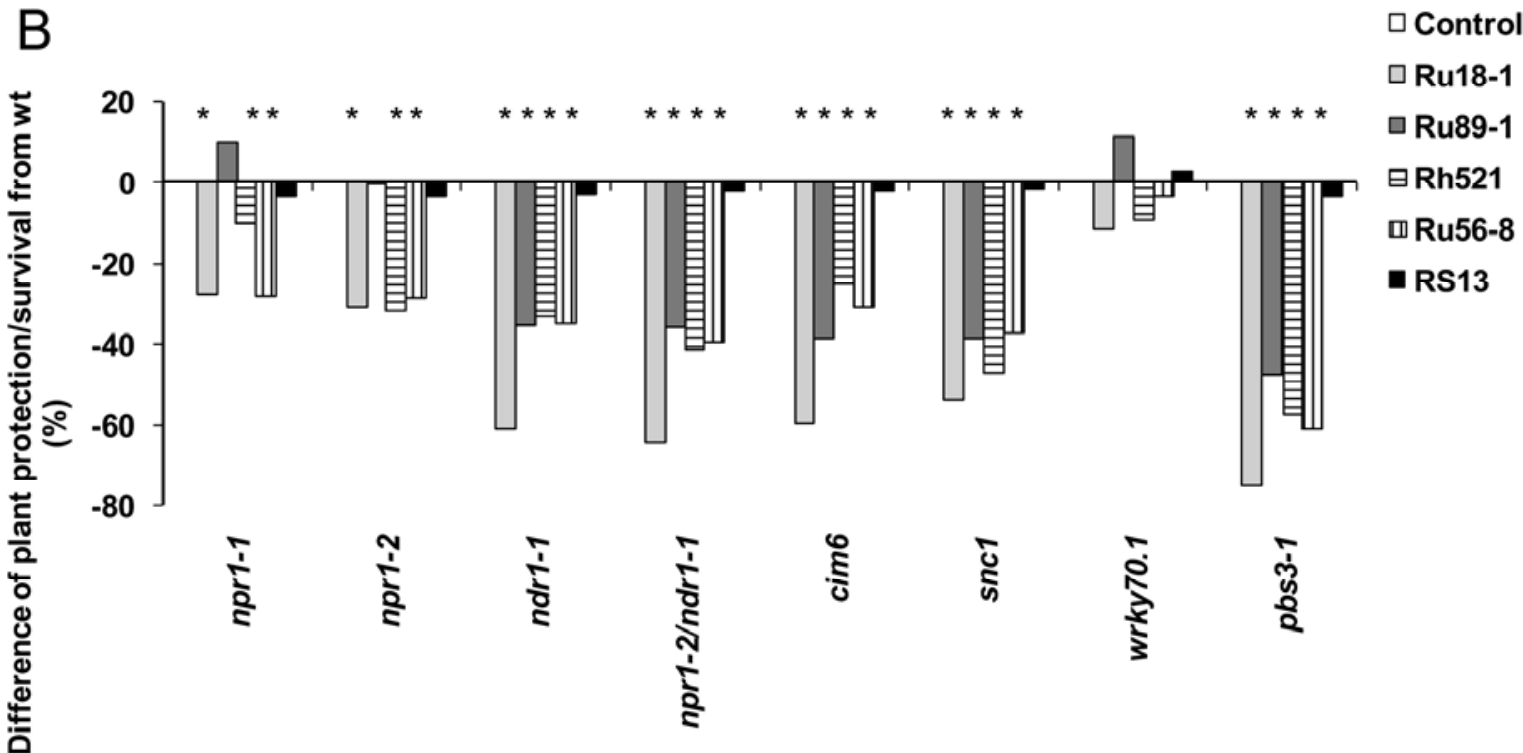

Plant genotype
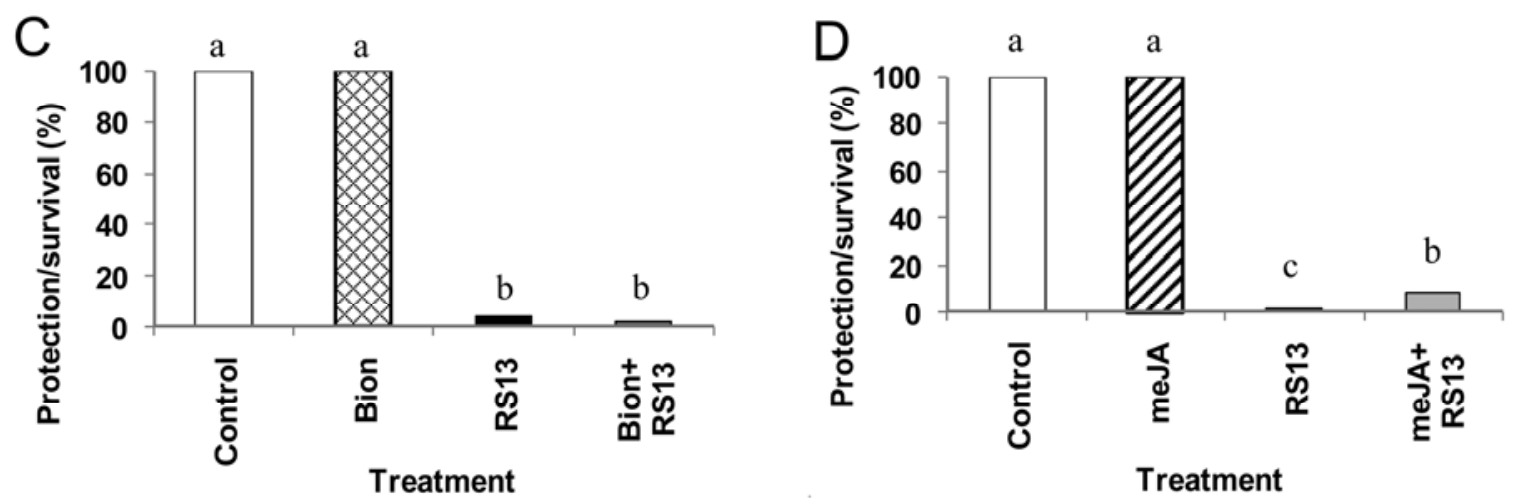

Fig. 4. Virulence and protection assays of Rhizoctonia isolates on Arabidopsis thaliana plants: A, virulence; B, protection; C, Bion application; and D, methyl jasmonate (MeJA) application. Treatments: control = noninoculated plants; RS13 = pathogenic Rhizoctonia isolate; Ru18-1, Ru89-1, Rh521, and Ru56-8 = hypovirulent Rhizoctonia isolates; Bion $=0.5 \mu \mathrm{M}$ Bion; Bion+RS13 = Bion followed by challenge inoculation; MeJA = 2\% MeJA in 20\% ethanol; MeJA+RS13 = MeJA followed by challenge inoculation. Plants were challenge-inoculated with the pathogen RS13 $48 \mathrm{~h}$ after initial inoculation. Columns marked with an asterisk are significantly different from the values of the same treatment on wild-type (wt) plants (two way analysis of variance followed by Tukey's highly significant difference, $\alpha=0.05, P=0.00$ for either virulence or protection assays). Results of treatments with challenge inoculation indicate the percent protection of plants, while other treatments indicate the percent survival. 
Changes in virulence or protection by Rhizoctonia isolates on A. thaliana mutants in defense pathways, compared with virulence and protection of the wt. In order to identify genes involved in the induced resistance pathways, which were triggered in plants colonized by hypovirulent Rhizoctonia isolates, changes in virulence of the isolates and the protection ability of $A$. thaliana mutants harboring defected defense-related genes were examined and compared with the reactions obtained on wt plants.

A. thaliana npr1-1,2. No difference was observed in virulence of the Rhizoctonia isolates on the nprl mutants compared with that on wt plants (Fig. 4A). Most of the hypovirulent isolates tested (Ru18-1, Rh521, and Ru56-8) did not protect the nprl-1 mutant to the same extent that they protected the wt plants. For example: Ru18-1 and Ru56-8 protections were reduced by $28 \%$ (Fig. 4B). A similar trend was observed with nprl-2 protection.

A. thaliana ndr1-1. No difference was observed in virulence of the Rhizoctonia isolates on the $n d r l-1$ mutant compared with that on wt plants (Fig. 4A). However, there was a significant decrease in the protection ( $>60 \%$ for Ru18-1 and $>30 \%$ for the rest of the tested hypovirulent isolates) of this mutant (Fig. 4B).

A. thaliana double mutant npr1-2/ndr1-1. This mutant contains the nprl-2 and ndrl-1 mutations. The hypovirulent isolate Ru56-8 was slightly virulent on this mutant (8\% mortality). Protection of $n d r 1-1$ plants by all of the hypovirulent isolates was impaired compared with that on the wt plants. The mutant nprl-2 was protected significantly better $(\alpha=0.05)$ than $n d r 1-1 / n p r 1-2$ (except by isolate Ru56-8, which protected both $n d r 1-1 / n p r l-2$ and nprl-2 plants to the same extent).

A. thaliana cim6 and snc1. These mutants constitutively express genes involved in the SAR pathway. Isolates Rh521 and Ru56-8 were slightly virulent on these mutants (6 and 3\% mortality for $\operatorname{cim} 6$ and 8 and $14 \%$ for sncl, respectively) (Fig. 4B), which may be the consequence of impaired fitness due to constitutive SAR expression. The protection of these mutants by the hypovirulent isolates was impaired compared with that of the wt $A$. thaliana plants (Fig. 4B).

A. thaliana wrky70.1. This mutant was not oversusceptible to colonization by the different Rhizoctonia isolates (Fig. 4A) and there was no difference in protection of the wt and mutant plants by any of the tested hypovirulent isolates (Fig. 4B).

A. thaliana pbs3-1. There was no increase in virulence of the isolates on the pbs3-1 mutant plants (Fig. 4A) but all of the hypovirulent isolates protected this mutant at a reduced level compared with that of the wt plants (Fig. 4B).

Evaluation of the protection levels induced in wt $A$. thaliana plants by the exogenic SAR or ISR inducers. Bion did not protect the plants against the pathogenic Rhizoctonia isolate (Fig. 4C); likewise, MeJA provided a very low protection, significantly less than the protective hypovirulent isolates (Fig. 4D).

Evaluation of defense-related gene expression in wt $A$. thaliana induced by colonization with hypovirulent Rhizoctonia isolates, Bion, or MeJA using qRT-PCR. The genes tested were induced either via SAR (PAD4, PR5), ISR (LOX1, LOX2, CORI3, PDF 1.2), or phytoalexin camalexin production pathway $(P A D 3)$ or were involved in ROS triggering (NDRl). The hypovirulent Rhizoctonia isolates Ru18-1 and Ru56-8 induced PR5 (SAR-related), LOX2, PDF1.2 (ISR), and PAD3 (phytoalexin pathway) genes in wt $A$. thaliana plants (Fig. 5). The LOX1 and CORI3 genes (ISR pathway) were induced only in plants colonized with the hypovirulent isolate Ru56-8. PAD4 expression did not increase in the colonized plants, indicating that the increased expression of PAD4 may not be the essential component in the induction of SAR by the hypovirulent isolates. Also, expression levels of Bion and MeJA were used to induce either SAR or ISR, respectively, in order to provide an insight on how the tested genes would react when either defense system was induced, as well as comparing this expression pattern with the one induced by plant colonization with the hypovirulent Rhizoctonia isolates. MeJA-treated plants responded with higher levels of

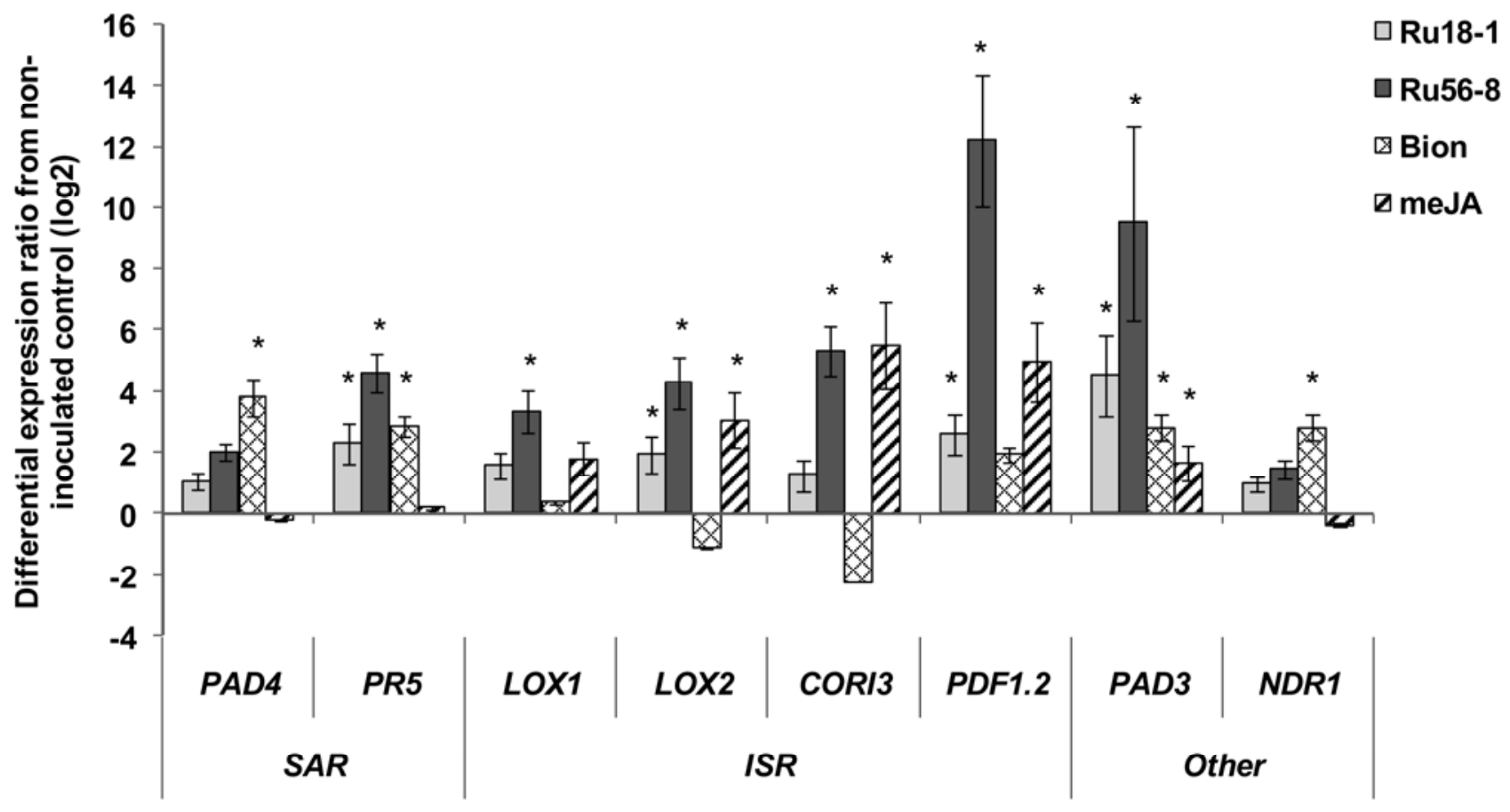

Genes tested

Fig. 5. Expression ratio of genes induced by hypovirulent Rhizoctonia isolates, methyl jasmonate (MeJA), or Bion compared with noninoculated control of wildtype (wt) Arabidopsis thaliana plants. Control = noninoculated plants; = hypovirulent Rhizoctonia isolates; Bion $=0.5 \mu \mathrm{M}$ Bion; and MeJA $=2 \%$ MeJA in $20 \%$ ethanol. Data were analyzed using the REST program (41). Results with absolute values $>2$, which were significantly different (relocation randomization test, $P<$ 0.05) from the expression of these genes in noninoculated control plants, are marked with an asterisk. SAR $=$ systemic acquired resistance and ISR $=$ induced systemic resistance. 
mRNA of all the tested genes involved in the ISR pathway, except for LOX1. The SAR-related genes (PAD4 and PR5) were not induced in MeJA-treated plants or in the ROS-related gene NDRl. Bion-treated plants had significantly higher levels of mRNA of both SAR-related genes, PAD3 and $n d r l$. None of the ISR-related genes were induced in Bion-treated plants.

Evaluation of expression levels of defense-related genes in defense-impaired $A$. thaliana mutants npr1-1 and ndr1-1. The differences in expression levels of the tested genes in noninoculated nprl-1 and ndrl-1 mutant plants compared with those in the wt plants indicated that the mutations reduced the basic levels of some of the tested genes (Fig. 6A). mRNA expression levels of the SAR-related genes PAD4 and PR5 were lower in both $n d r l-1$ and nprl-1 mutants compared with those in wt plants. In addition, mRNA expression levels of the ISR-related genes LOX1 and CORI3, but not that of LOX2 gene expression, were lower in both tested mutants. Mutant nprl-1 also expressed lower levels of PDF1.2 and NDRI mRNA than those in the wt plants.

Colonization of the nprl-1 mutant with the hypovirulent isolates Ru18-1 and Ru56-8 induced expression of the genes PDF1.2 and $P A D 3$ (Fig. 6B) in the plants. However, unlike the wt plants, there was no induction of expression levels of $P R 5, L O X 2$, or CORI3 when the plants were precolonized with isolate Ru56-8. Although the expression level of PDF1.2 was induced in nprl-1 mutants by inoculation of Ru56-8 or Ru18-1 isolates, the basic expression level of this gene in nprl-1 mutants was lower than that in the wt plants (Fig. 6A).

When $n d r 1-1$ plants were colonized, the hypovirulent isolates Ru18-1 and Ru56-8 induced PR5 but not PAD4 expression levels (Fig. 6C). This may indicate that the SAR pathway was induced, although not necessarily through the PAD4 gene pathway. Because the basic expression of the genes PAD4 and PR5 was lower in the ndrl-1 mutants than that in the wt plants (Fig. 6A), the SAR reaction induced in the $n d r l-1$ mutant is most likely lower than that induced in the wt. The PDF1.2 gene was induced by both of the hypovirulent isolates (Fig. 6C), and the mRNA levels of the CORI3 gene increased only after colonization of plants by the Ru56-8 isolate, similar to the colonized wt plants. LOX1 and LOX2 expression levels did not change when the ndr11 plants were colonized by either of the hypovirulent isolates (expression of the LOX2 gene was induced in the wt plants by both of the hypovirulent isolates, Ru18-1 and Ru56-8, and the expression of the $L O X 1$ gene increased in wt plants only when the plants were colonized with Ru56-8).

\section{DISCUSSION}

The present study clearly demonstrated that the three resistance pathways SAR, ISR, and the phytoalexins production system were induced by colonization with the protective hypovirulent Rhizoctonia isolates that protected plants against pathogenic $R$. solani.

A previous method for assessing susceptibility of $A$. thaliana mutants (40) was insufficient for the requirements of the present study; therefore, an improved assay was developed in this work to provide accuracy, reliability, and quantitative data, saving time and space, having a minimal effect of interfering external factors, and being capable of examining large numbers of plant genotypes and Rhizoctonia isolates. The protection assay results indicated that, although all of the hypovirulent isolates protected the plants, the isolates differed in the protection levels. These results, the difference in the protection of the different $A$. thaliana mutants, and the diversity in the profiles of genes induction of the colonized plants indicate that the different hypovirulent isolates may differ in the modes of action by which they protect plants.

SAR involvement in protection of colonized plants by the hypovirulent isolates was examined partly by using the $\operatorname{cim} 6$, sncl, and pbs3-1 mutants. Mutants cim6 and sncl constitutively express the SAR pathway $(31,35)$. The sncl mutation in the Toll interleukin 1 receptor nucleotide-binding LRR-type resistance gene resulted in a constitutive activation of an $R$ gene and, consequently, SAR. This phenotype is dependent on PAD4 and is partially dependent on SA (59). Constitutive SAR expression in cim6 is dependent on SA accumulation (34), resulting in an increased resistance to fungal pathogens (35). The protection of both cim 6 and $s n c 1$ by the hypovirulent isolates was decreased compared with the wt plants. Because there is a trade-off between the SAR and ISR pathways, it is possible that a constitutive expression of the SAR pathway led to a reduced effect of the ISR pathway (3), or that another resistance mechanism is responsible for the reduction of disease severity caused by pathogenic Rhizoctonia spp. which is impaired when the SAR pathway is constitutively expressed. Alternatively, diminished fitness may also result in reduced resistance of the constitutively expressing SAR mutants compared with that of the wt plants, as was previously reported (12). The pbs3-1 mutant is defective in the gh3.12 gene, which results in reduced SA accumulation and SA-dependent gene expression (38). Protection of this mutant by the tested hypovirulent isolates was decreased. In addition to playing a key role in the SAR system, SA is also essential for the establishment of certain pathways of the ISR system (22). Therefore, it is likely that both the SAR and ISR systems are reduced in pbs3-1 mutant plants, or even completely inhibited. The decreased protection of these mutants by the hypovirulent isolates could be due to the impaired induction of SAR, ISR, or both. Monitoring induction of SAR-related genes revealed that Bion induced both of the tested SAR-related genes (PAD4 and PR5) in the plants, although the resistance was not evident against the pathogenic isolate. The hypovirulent isolates induced only one of the monitored SAR genes (PR5, which is expressed at the end of the SAR pathway). Therefore, although the SAR system was induced by the hypovirulent isolates and Bion, it did not protect the plants against this pathogen.

ISR involvement in protection of colonized plants by the hypovirulent isolates was examined partly by using the mutant wrky70-1, which is defective in the gene that codes a transcription factor balancing the JA- and SA-dependent responses, by inhibiting the ISR pathway (30), working downstream from the ROS defense reaction and SA induction (29). As demonstrated in Figure 1, wrky70-1 protection was similar to the protection induced in wt plants by the hypovirulent Rhizoctonia isolates. It is plausible to assume that the hypovirulent isolates induce the ISR pathway but not the SAR pathway. However, this hypothesis was not supported by quantitative real-time PCR, because it is apparent that the SAR as well as ISR pathways were induced by the hypovirulent isolates. Another possibility to explain the unchanged protection levels of the wrky70-1 plants compared with that of the wt is that ISR is the major mechanism of protection against the pathogenic Rhizoctonia isolate. This theory is supported by reduced protection of the constitutively expressing SAR mutants cim6 and sncl and well-established research indicating that necrotrophic pathogens induce the ISR pathway in plants (43). The hypovirulent Rhizoctonia isolates provided relatively high protection levels while the MeJA-induced protection was mild; the difference probably resulted from the combined defense modes triggered by the hypovirulent isolates, such as competition for space and infection sites, and triggering of a number of defense mechanisms, such as local resistance, SAR, and ISR.

The hypovirulent Rhizoctonia isolates also induced genes involved in phytoalexin production. This supports previous reports which demonstrated that phytoalexins play an important role in plant protection against Alternaria spp., a necrotrophic fungal pathogen (52), and also that ISR and camalexin production have a shared degree of "cross-talk" (16), implying combined protection of ISR and phytoalexins. 


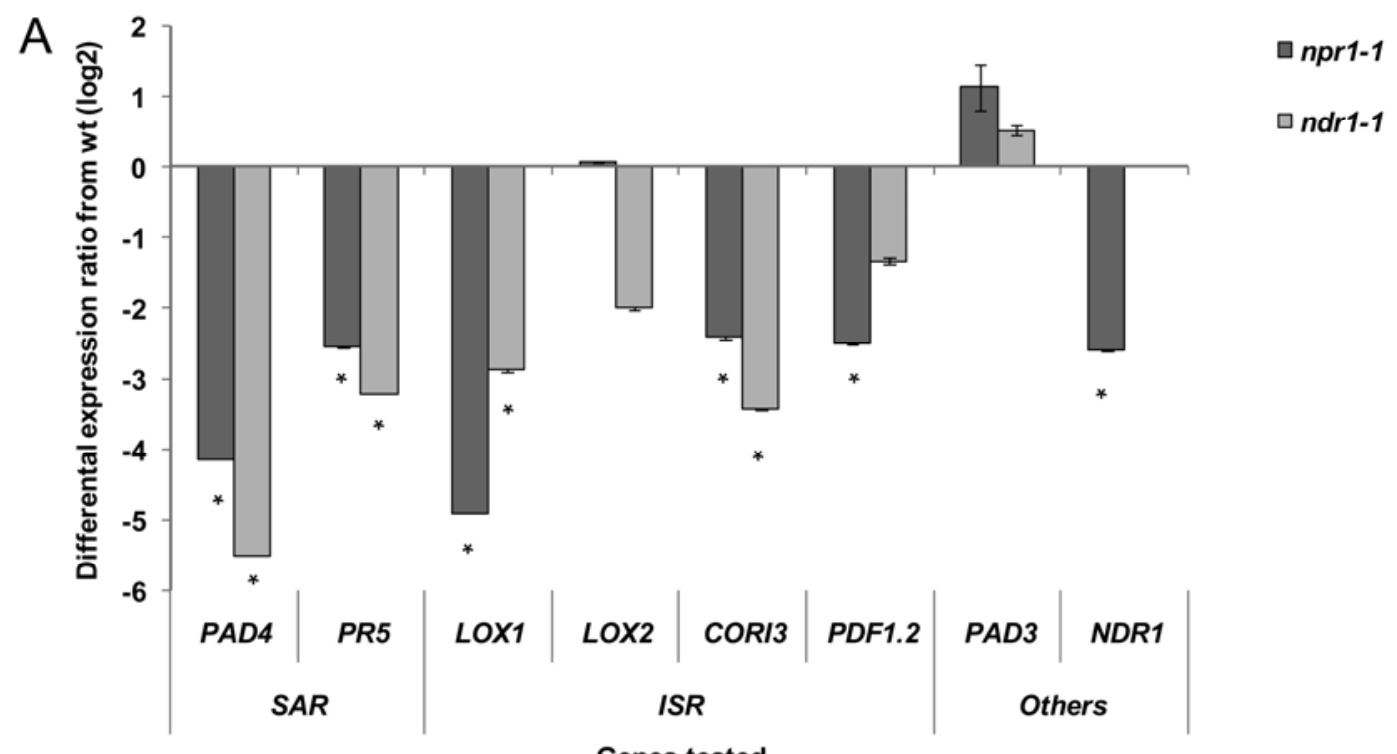

Genes tested
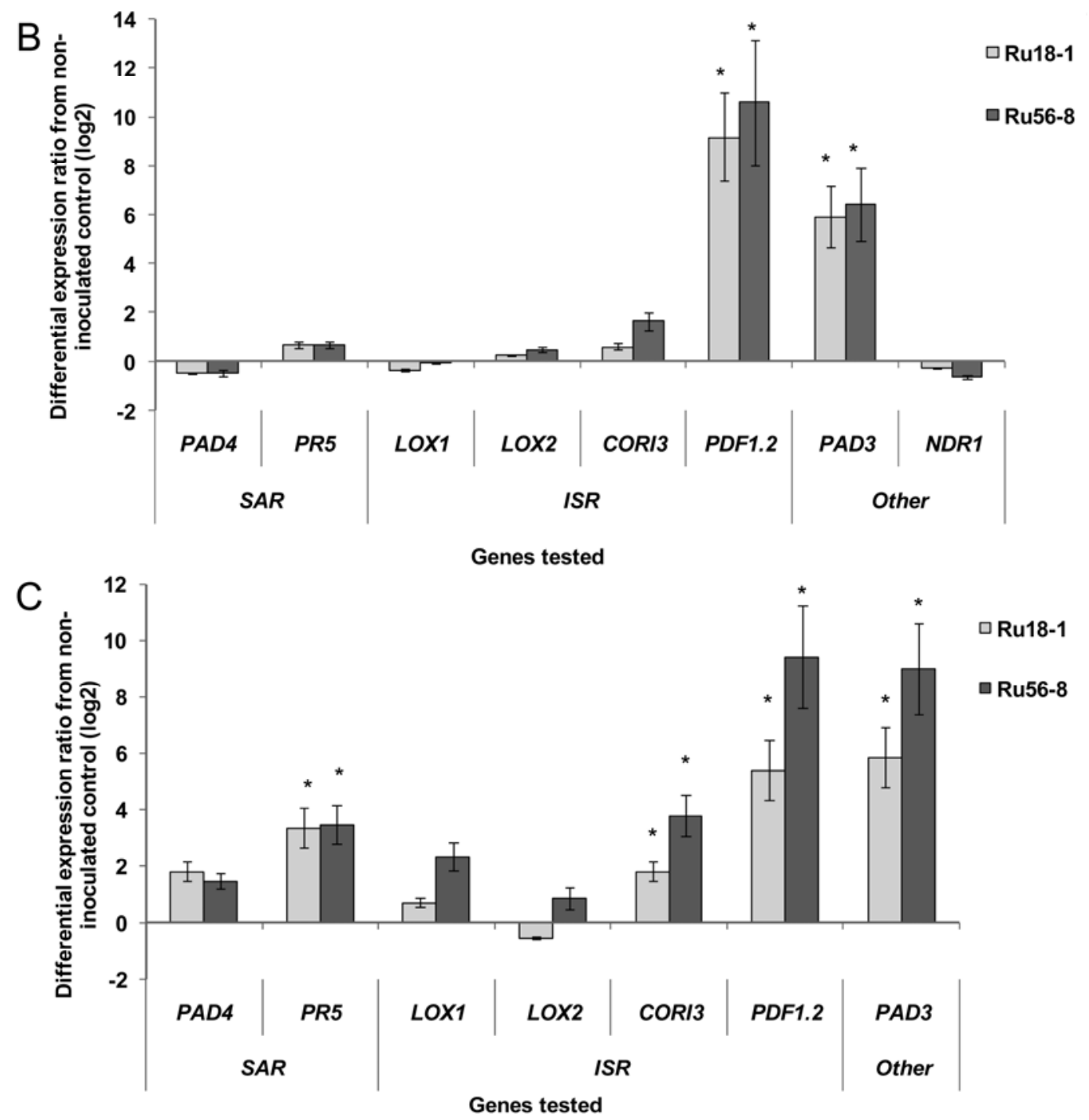

Fig. 6. Expression ratio of genes in nprl-1 and ndrl-1 mutants. A, Noninoculated compared with that of the wild-type (wt) Arabidopsis thaliana plants; B, induced by hypovirulent Rhizoctonia isolates in Arabidopsis thaliana nprl-1 mutant compared with that in nprl-1 noninoculated controls; C, induced by hypovirulent Rhizoctonia isolates in A. thaliana ndr1-1 mutant compared with that in $n d r 1-1$ noninoculated controls. NDR1 expression in mutant $n d r 1-1$ was not tested because it is a null mutant for this gene. Tested genes are described in Figure 1. Results with absolute values $>2$, that are significantly different (relocation randomization test, $P<0.05$ ) from the expression of these genes in the comparable wt plants, are marked with an asterisk. SAR $=$ systemic acquired resistance and ISR $=$ induced systemic resistance. 
Both of the induced systemic pathways (SAR and ISR) require a functioning NPR1 gene $(4,13)$. Protection levels of both $n p r l$ mutants were decreased by most of the hypovirulent Rhizoctonia isolates tested compared with the wt plants, except by isolate Ru89-1, which protected these mutants to a similar level as the wt plants. It is quite possible that Ru89-1 induced plant protection in a different way than the other tested hypovirulent isolates, or that the protection rendered by this isolate depended more upon local resistance and competition with the pathogen for infection sites and less on the ISR pathways, as shown in this study (Fig. 4B). The nprl-1 mutant is defective in the ankyrin-repeat domain of the NPRl gene (8). The protein is consequently miss-folded and loses its function in both SAR and ISR pathways (19). The point mutation in nprl-2 exchanges the amino acid cysteine with tyrosine (8) in the BTB/POZ domain, which participates in the co-induction of PR1 by NPR1 and TGA2 (44). The nprl-2 mutation is not complete and allows partial NPR1 activity (8). There was no difference between the protection of the two nprl mutants by the different hypovirulent isolates; hence, a complete loss of function of the NPR1 protein due to a miss-folding (nprl-1) did not reduce the protection (provided by the hypovirulent isolates) further than that resulting from a damaged NPR1 (nprl-2). The decreased protection of both nprl mutants could be a consequence of faulty growth of the hypovirulent isolate on the mutant, increased virulence of the pathogen (even though the hypovirulent isolates were no more virulent on this mutant than on the wt plants), defective induced resistance pathways (which are involved in the protection of the plants colonized by the hypovirulent isolates), or a default in the induction processes of the ISR pathways by the hypovirulent isolates. Monitoring SAR-related gene expression in the nprl-1 mutant revealed that the respective genes (PAD4 and PR5) were not expressed at the same levels in noninoculated plants compared with those in the wt plants and were not induced by colonization with the hypovirulent isolates in the nprl-1 mutant. Thus far, it is assumed that the SAR pathway is not functioning in this mutant, supported in previous reports, whereby nprl-1 plants did not express SAR-reporting signals $(4,8)$. Among the ISR-related tested genes, only the end-pathway-gene, $P D F 1.2$, was induced in the nprl-1 mutant by colonization of the plants with the hypovirulent isolates Ru18-1 and Ru56-8. Because the ISR reaction (as well as SAR) is a complicated network rather than a direct pathway, the hypovirulent isolates may induce ISR through a number of steps, one or some of which do not require a functional NPRl gene. Considering the low expression levels of the ISRrelated genes LOXI,CORI3, and PDF1.2 in the noncolonized nprl-1 plants compared with those in the wt plants, it is likely that induction of ISR in the nprl-1 mutant by the hypovirulent isolates is incomplete. Expression of NDRl was lower in the nprl-1 mutant than in wt plants, which might have resulted in a failure of plants to recognize the fungus (17) or a defective response of the oxidative burst (60).

The ndrl-1 mutant carries a null allele for this gene and, therefore, is defective in an array of reactions dependent on ROS accumulation and activation (11) and a resistance response via an EST1-PAD4 independent pathway (1). The tested hypovirulent isolates did not protect the ndrl-1 mutant plants to the same extent as they did in the wt plants. This could be due to a damaged oxidative burst (11) or other reactions involved in resistance, which require ROS for activation of certain genes such as $P D F 1.2$ (23).

Quantitative real-time PCR indicated that the noncolonized ndr1-1 mutant plants expressed lower mRNA levels of the two tested ISR-related genes ( $L O X 1$ and CORI3) than those in the noncolonized wt plants. Because the $n d r l-1$ mutant is a null mutant in this gene, its expression was not monitored in these plants. It may be concluded that expression of some of the SARand ISR-related genes was reduced in the noninoculated $n d r l-1$ plants compared with that in wt plants. This may lead to a faulty expression in the resistance pathways. When induction of the SAR- and ISR-related genes was examined in response to colonization with hypovirulent isolates in $n d r l-1$ mutant plants, the SAR-related $P R 5$ and ISR-related $P D F 1.2$ genes were induced (Fig. 6C). In addition, the CORI3 gene was induced when plants were colonized with the hypovirulent isolate Ru56-8 but not with Ru18-1. When gene expression of wt plants was evaluated, there was also an induction of the LOX1 gene in plants colonized with Ru56-8 (but not with Ru18-1), and induction of the LOX2 gene by both of the hypovirulent isolates. These results indicate that some aspects of the SAR and ISR pathways might have been negatively affected by the $n d r l-1$ mutation. In summary, there was still an induction of the SAR and ISR pathways but the expression levels of genes related to both of the pathways were reduced in the $n d r 1-1$ mutant. In addition, some of the ISRrelated genes that were induced in the wt plants by colonization with the hypovirulent isolates were not induced in colonized $n d r 1-1$ plants.

The nprl-2/ndrl-1 is a double mutant in the two genes NPRl and NDR1, which have been found to act additively rather than synergistically, where SAR was induced (60). One of the hypovirulent isolates (Ru56-8) was slightly virulent on these mutant plants and the protection levels of this mutant by the hypovirulent isolates were lower than that of the same isolates on the wt plants. When protection levels of the mutant ndrl-1, nprl2, and nprl-2/ndrl-1 plants were compared, protection levels of $n p r 1-2$ were higher than those of the $n d r 1-1$ and nprl-2/ndrl-1 plants but there was no difference between the ndrl-1 and nprl2/ndrl-1 protection levels induced by the different hypovirulent isolates. These results confirm those of Zhang and Shapiro (60), indicating that the NDRl and NPRl genes do not act synergistically.

The SAR and ISR pathways are intertwined networks with shared components. These components might act as either inducers in one pathway or inhibitors in the other, similar to the EST1 and PAD4 genes (3). Other gene products may be required by both the SAR and ISR pathways to assemble a complete reaction, such as NPR1 (14). On the other hand, there is redundancy in both of these pathways (61), which may mask a defective component in a resistance pathway by the activity of one or the other.

Colonization of $A$. thaliana plants by hypovirulent Rhizoctonia isolates induced both SAR-, ISR-, and phytoalexin-related genes. Previous studies have indicated that necrotrophic pathogens induced ISR in plants and that this system was involved in protection against certain pathogens (4). The hypovirulent isolates also induced ISR-related genes, as did the treatment with MeJA. Induction of both the ISR and SAR resistance pathways was also demonstrated in A. thaliana by van Wees et al. (53); however, to induce both systems simultaneously, application of two different microorganisms was required. When both SAR and ISR were simultaneously activated, an additive effect of induced resistance was observed (15). Therefore, it is plausible to assume that a biocontrol agent which triggers both of the ISR and SAR pathways may provide improved protection compared with one which activates only a single system.

In conclusion, the results of the present study confirmed that the hypovirulent Rhizoctonia isolates used in this study induced genes involved in both SAR and ISR pathways, and the production of phytoalexins in the colonized plants. Previous studies (49) have indicated that competition may play an important role in the modes of action of plant protection as a result of colonization with hypovirulent Rhizoctonia isolates. Additional work is required to evaluate the relative contribution of the systemic induced resistance revealed in the present study, as well as competition for space, infection sites, and local induced resistance. 


\section{ACKNOWLEDGMENTS}

We thank B. Staskawicz (University of California, Berkeley), X. Li (University of British Colombia, Vancouver, Canada), and R. Innes (University of Indiana, Bloomington) for providing the Arabidopsis thaliana mutants used in this study.

\section{LITERATURE CITED}

1. Aarts, N., Metz, M., Holub, E., Staskawicz, B. J., Daniels, M. J., and Parker, J. E. 1998. Different requirements for EDS1 and NDR1 by disease resistance genes define at least two $R$ gene-mediated signaling pathways in Arabidopsis. Proc. Natl. Acad. Sci. USA 95:10306-10311.

2. Bannenberg, G., Martinez, M., Hamberg, M., and Castresana, C. 2009. Diversity of the enzymatic activity in the lipoxygenase gene family of Arabidopsis thaliana. Lipids 44:85-95.

3. Bari, R., and Jones, J. D. G. 2009. Role of plant hormones in plant defense responses. Plant Mol. Biol. 69:473-488.

4. Beckers, G. J. M., and Spoel, S. H. 2006. Fine-tuning plant defense signaling: salicylate versus jasmonate. Plant Biol. 8:1-10.

5. Bell, E., Creelman, R. A., and Mullet, J. E. 1995. A chloroplast lipoxygenase is required for wound-induced jasmonic acid accumulation in Arabidopsis. Plant Biol. 92:8675-8679.

6. Bottcher, C., Westphal, L., Schmotz, C., Prade, E., Scheel, D., and Glawischnig, E. 2009. The nultifunctional enzyme CYP71B15 (PHYTOALEXIN DEFICIENT3) converts cysteine-indole-3-acetonitrile to camalexin in the indole-3-acetonitrile metabolic network of Arabidopsis thaliana. Plant Cell 1830-1845.

7. Brodersen, P., Petersen, M., Nielsen, H. B., Zhu, S., Newman, M. A., Shokat, K. M., Rietz, S., Parker, J., and Mundy, J. 2006. Arabidopsis MAP kinase 4 regulates salicylic acid- and jasmonic acid/ethylenedependent responses via EDS1 and PAD4. Plant J. 47:532-546.

8. Cao, H., Glazebrook, J., Clarke, J. D., Volko, S., and Dong, X. 1997. The Arabidopsis NPR1 gene that controls systemic acquired resistance encodes a novel protein containing ankyrin repeats. Cell 88:57-63.

9. Cardinale, F., Ferraris, L., Valentino, D., and Tamietti, G. 2006. Induction of systemic resistance by a hypovirulent Rhizoctonia solani isolate in tomato. Physiol. Mol. Plant Pathol. 69:160-171.

10. Castillo, M. C., Martinez, C., Buchala, A., Metraux, J. P., and Leon, J. 2004. Gene-specific involvement of $\beta$-oxidation in wound-activated responses in Arabidopsis. Plant Physiol. 135:85-94.

11. Century, K. S., Shapiro, A. D., Repetti, P. R., Dahlbeck, D., Holub, E., and Staskawicz, B. J. 1997. NDR1 a pathogen-induced component required for Arabidopsis disease resistance. Science 278:1963-1965.

12. Cipollini, D. F. 2002. Does competition magnify the fitness costs of induced responses in Arabidopsis thaliana? A manipulative approach. Oecologia 131:514-520.

13. Dong, X. 1998. SA, JA, ethylene and disease resistance in plants. Curr. Opin. Plant Biol. 1:316-323.

14. Dong, X. 2004. NPR1, all things considered. Curr. Opin. Plant Biol. 7:547-552.

15. Durrant, W. E., and Dong, X. 2004. Systemic acquired resistance. Annu. Rev. Phytopathology 42:185-209.

16. Feys, B. J., and Parker, J. E. 2000. Interplay of signaling pathways in plant disease resistance. Trends Genet. 16:449-455.

17. Glazebrook, J. 1999. Genes controlling expression of defense responses in Arabidopsis. Curr. Opin. Plant Biol. 2:280-286.

18. Glazebrook, J. 2001. Genes controlling expression of defense responses in Arabidopsis-2001 status. Curr. Opin. Plant Biol. 4:301-308.

19. Glazebrook, J., Chen, W., Estes, B., Chang, H. S., Nawrath, C., Metrraux, J. P., Zhu, T., and Katagiri, F. 2003. Topology of the network integrating salicylate and jasmonate signal transduction derived from global expression phenotyping. Plant J. 34:217-228.

20. Harris, A. R. 2000. Solid formulations of binucleate Rhizoctonia isolates suppress Rhizoctonia solani and Pythium ultimum in potting medium. Microbiol. Res. 154:333-337.

21. Harris, A. R., Schisler, D. A., Neate, S., and Rider, M. H. 1993. Suppression of damping off caused by Rhizoctonia solani and growth promotion in bedding plants by binucleate Rhizoctonia spp. Soil Biol. Biochem. 25:263-268.

22. Heil, M., and Bostock, R. M. 2002. Induced systemic resistance (ISR) against pathogens in the context of induced plant defenses. Ann. Bot. 89:503-512.

23. Huffaker, A., Pearce, G., and Ryan, C. A. 2006. An endogenous peptide signal in Arabidopsis activates components of the innate immune response. Proc. Natl. Acad. Sci. USA 103:10098-10103.

24. Jabaji-Hare, S., Chamberland, H., and Charest, P. M. 1999. Cell wall alterations in hypocotyls of bean seedlings protected from Rhizoctonia stem canker by a binucleate Rhizoctonia isolate. Mycol. Res. 103:1035-1043.
25. Jirage, D., Tootle, T. L., Reuber, T. L., Frost, L. N., Feys, B. J., Parker J. E., Ausubel, F. M., and Glazebrook, J. 1999. Arabidopsis thaliana PAD4 encodes a lipase-like gene that is important for salicylic acid signaling. Proc. Natl. Acad. Sci. USA 96:13583-15388.

26. Jones, P. R., Manabe, T., Awazuhara, M., and Saito, K. 2003. A new member of plant CS-lyases. J. Biol. Chem. 278:10291-10296.

27. Kawamura, Y., Takenaka, S., Hase, S., Kubota, M., Ichinose, Y., Kanayama, Y., Nakaho, K, Klessing, D. F., and Takahashi, H. 2009. Enhanced defense responses in Arabidopsis induced by the cell wall protein fractions from Pythium oligandrum require SGT1, RAR1, NPR1 and JAR1. Plant Cell Physiol. 50:924-934.

28. Kombrink, E., and Somssich, I. E. 1997. Pathogenesis-related proteins and plant defense. Plant relationships, part B. Pages 107-128 in: The Mycota. K. Essesr and P. A. Lemke, eds. Springer-Verlag, Berlin.

29. Knoth, C., Ringler, J., Dangl, J., and Eulgem, T. 2007. Arabidopsis WRKY70 is required for full RPP4-mediated disease resistance and basal defense against Hyaloperonospora parasitica. Mol. Plant-Microbe Interact. 20:120-128.

30. Li, J., Brader, G., Kariola, T., and Palva, T. 2006. WRKY70 modulates the selection of signaling pathways in plant defense. Plant J. 46:477-491.

31. Li, X., Clarke J. D., Zhang, Y., and Dong, X. 2001. Activation of an EDS1 mediated R gene pathway in the snc1 mutant lead to constitutive, NPR1independent pathogen resistance. Mol. Plant-Microbe Interact. 14:11311139.

32. Lopez, M. A., Bannenberg, G., and Castresana, C. 2008. Controlling hormone signaling is a plant and pathogen challenge for growth and survival. Curr. Opin. Plant Biol. 11:420-427.

33. Lu, H. 2009. Dissection of salicylic acid-mediated defense signaling networks. Plant Signal. Behav. 4:713-717.

34. Maleck, K., Levine, A., Eulgem, T., Morgan, A., Schmid, J., Lawton, K.A., Dangl, J. L., and Dietrich, R. A. 2000. The transcriptome of Arabidopsis thaliana during systemic acquired resistance. Nat. Genet. 26:403-410.

35. Maleck, K., Neuenschwander, U., Cade, R. M., Dietrich, R. A., Dangl, J. L., and Ryals, J. A. 2002. Isolation and characterization of broadspectrum disease-resistant Arabidopsis mutants. Genetics 160:1661-1671.

36. Melan, M. A., Dong, X., Endara, M. E., Davis, K. R., Ausubel, F. M., and Peterman, T. K. 1993. An Arabidopsis thaliana lipoxygenase gene can be induced by pathogens, abscisic acid and methyl jasmonate. Plant Physiol. 101:441-450.

37. Murashige, T., and Skoog, F. 1962. A revised medium for rapid growth and bioassays with tobacco tissue cultures. Physiol. Plant. 15:473-497.

38. Okrent, R. A., Brooks, M. D., and Wildermuth, M. C. 2009. Arabidopsis GH3.12 (PBS3) conjugates amino acids to 4-substituted benzoates and is inhibited by salicylate. J. Biol. Chem. 284:9742-9754.

39. Penninckx, I. A. M. A, Eggermont, K., Terras, F. R. G., Thomma, B. P. H. J., De Samblanx, G. W., Buchala, A., Metraux, J. P., Manners, J. M., and Broekaert, W. F. 1996. Pathogen-induced systemic activation of a plant defensin gene in Arabidopsis follows a salicylic acid-independent pathway. Plant Cell 8:2309-2323.

40. Perl-Treves, R., Foley, R. C., Chen, W., and Singh, K. B. 2004. Early induction of the Arabidopsis GSTF8 promoter by the fungal pathogen Rhizoctonia solani. Mol. Plant-Microbe Interact. 17:70-80.

41. Pfaffl, M. W., Horgan, G. W., and Dempfle, L. 2002. Relative expression software tool (REST for group-wise comparison and statistical analysis of relative expression results in real-time PCR. Nucleic Acids Res. 30:e36.

42. Pieterse, C. M. J., van der Ent, S., van Pelt, J. A., and van Loon, L.C. 2007. The role of ethylene in rhizobacteria-induced systemic resistance (ISR). Advances in plant ethylene research. Pages 325-331 in: Proc. 7th Int. Symp. Plant Hormone Ethylene. Springer, Dordrecht, the Netherlands

43. Pozo, M. J., van Loon, L. C., and Pieterse, C. M. J. 2005. Jasmonatessignals in plant microbe interactions. J. Plant Growth Regul. 23:211-222.

44. Rochon, A., Boyle, P., Wignes, P., Fobert, P. R., and Despres, C. 2006. The Co activator function of Arabidopsis NPR1 requires the core of its $\mathrm{BTB} / \mathrm{POZ}$ domain and the oxidation of C-terminal cysteines. Plant Cell 18:3670-3685.

45. Schaller, A., and Stintzi, A. 2008. Jasmonate biosynthesis and signaling for induced plant defense against herbivory. Chapter 17 in: Induced Plant Resistance to Herbivoty. A. Schaller, ed. Springer Science and Business, Dordrecht, the Netherlands.

46. Sharon, M., Kuninaga, S., Hyakumachi, M., Naito, S., and Sneh, B. 2008. Classification of Rhizoctonia spp. using rDNA-ITS sequence analysis supports the genetic basis of the classical anastomosis grouping. Mycoscience 49:93-114.

47. Sneh, B., Burpee, L., and Ogoshi, A. 1991. Identification of Rhizoctonia Species. The American Phytopathological Society, St. Paul, MN.

48. Sneh, B., and Ichielevich-Auster, M. 1998. Induced resistance of cucumber seedlings caused by some non-pathogenic Rhizoctonia (np-R) isolates. Phytoparasitica 26:27-38. 
49. Sneh, B., Ichielevich-Auster, M., and Plaut, Z. 1989. Mechanism of seedling protection induced by a hypovirulent isolate of Rhizoctonia solani. Can. J. Bot. 67:2135-2141.

50. Talarczyk, A., and Hennig, J. 2001. Early defense responses in plants infected with pathogenic organisms. Cell. Biol. Mol. Lett. 6:955-970.

51. Ton, J., van Pelt, J. A., van Loon, L. C., and Pieterse, M. J. 2002. Differential effectiveness of salicylate-dependent and jasmonate/ethylene-dependent induced resistance in Arabidopsis. Mol. Plant-Microbe Interact. 15:27-34.

52. van Wees, S. C. M., Chang, H. S., Zhu, T., and Glazebrook, J. 2003. Characterization of the early response of Arabidopsis to Alternaria brassicicola infection using expression profiling. Plant Physiol. 132:606-617.

53. van Wees, S. C. M., de Swart, E. A. M., van Pelt, J. A., van Loon, L. C., and Pieterse, C. M. J. 2000. Enhancement of induced disease resistance by simultaneous activation of salicylate- and jasmonate-dependent defense pathways in Arabidopsis thaliana. Proc. Natl. Acad. Sci. USA 97:8711-8716.

54. van Wees, S. C. M., Luijendijk, M., Smoorenburg, I., van Loon, L. C., and Pieterse, C. M. J. 1999. Rhizobacteria-mediated induced systemic resistance (ISR) in Arabidopsis is not associated with a direct effect on expression of known defense-related genes but stimulates the expression of the jasmonate-inducible gene Atvsp upon challenge. Plant Mol. Biol. 41:537-549.
55. Vlot, A. C., Dempsey, D. A., and Klessig, D. F. 2009. Salicylic acid, multifaceted hormone to combat disease. Annu. Rev. Phytopathol. 47:177-206

56. Wade, H. E. 2006. Effects of acibenzolar-S-methyl on the suppression of Fusarium wilt of cyclamen. Crop Prot. 25:671-676.

57. Wen, K., Seguin, P., St.-Arnaud, M., and Jabaji-Hare, S. 2005. Real-time quantitative RT-PCR of defense-associated gene transcripts of Rhizoctonia solani-infected bean seedlings in response to inoculation with a nonpathogenic binucleate Rhizoctonia isolate. Phytopathology 95:345-353.

58. Xue, L. 1999. Systemic acquired resistance in bean seedlings and rice protected by non-pathogenic Rhizoctonia species. Ph.D. thesis, McGill University, Montreal.

59. Zhang, Y., Goritschnig, S., Dong, X., and Li, X. 2003. A gain-of-function mutation in a plant disease resistance gene leads to constitutive activation of downstream signal transduction pathways in suppressor of npr1-1, constitutive 1. Plant Cell 15:2636-2646.

60. Zhang, C., and Shapiro, A. D. 2002. Two pathways act in an additive rather than obligatorily synergistic fashion to induce systemic acquired resistance and $P R$ gene expression. BMC Plant Biol. 2:9-18.

61. Zhang, Y., Tessaro, M. J., Lassner, M., and Li, X. 2003. Knockout analysis of Arabidopsis transcription factors TGA2, TGA5, and TGA6 reveals their redundant and essential roles in systemic acquired resistance. Plant Cell 15:2647-2653. 